\title{
COMÉRCIO DE DENTES HUMANOS - AÇÕES PARA COMBATER ESSA PRÁTICA ILEGAL
}

\author{
HUMAN TEETH TRADE - ACTIONS TO COMBAT THIS \\ ILLEGAL PRACTICE
}

\author{
Dayliz Quinto Pereira ${ }^{1}$ \\ Isabelle Maria Gonzaga de Mattos Vogel ${ }^{2}$
}

Recebido em 22/09/2020

Aceito em 03/11/2020

\begin{abstract}
Resumo: O Biobanco de Dentes Humanos (BDH) é uma instituição que visa captar, armazenar e emprestar dentes humanos para treinamento pré-clínico de estudantes ou pesquisas científicas, além de propiciar a valorização do dente como um órgão do corpo humano e proteger, através da biossegurança, os agentes envolvidos com o manuseio de unidades dentárias, evitando infecções cruzadas. O BDH também tem papel fundamental no combate ao comércio ilegal de dentes ainda presente em muitas Faculdades de Odontologia. Mas, a obtenção de estruturas dentárias para atividades no âmbito acadêmico muitas vezes é proveniente do comércio em cemitérios, clínicas odontológicas e até pelos próprios funcionários das faculdades, o que remete a uma discussão no campo da Ética e legalidade dessa atitude. Tendo em vista que os acadêmicos necessitam da prática pré-clínica durante o curso de Odontologia, as instituições de ensino devem estar atentas a procedência dos dentes. Por isso, este relato de experiência tem como objetivo demonstrar ações extensionistas voltadas para o combate ao comércio ilegal de dentes através de visitas aos cemitérios da cidade com o intuito de promover conscientização dos coveiros acerca dos preceitos éticos, legais e biológicos que envolvem o comércio de dentes.
\end{abstract}

Palavras-chave: Odontologia, Ética, Biossegurança

Abstract: The Human Teeth Biobank (BDH) is an institution that aims to capture, store and lend human teeth for pre-clinical training of students or scientific research, in addition to promoting the valorization of the tooth as an organ of the human body and protecting, through biosafety, the agents involved with the handling of dental units, avoiding cross infections. BDH also plays a fundamental role in combating the illegal trade in teeth that is still present in many dental schools. However, obtaining dental structures for activities in the academic field often comes from commerce in cemeteries, dental clinics and even by the employees of the colleges, which leads to a discussion in the field of ethics and the legality of this attitude. Bearing in mind that academics need pre-clinical practice during the Dentistry course, educational institutions must be aware of the origin of the teeth. For this reason, this experience report aims to demonstrate

1 Universidade Estadual de Feira de Santana, Bahia.

2 Universidade Estadual de Feira de Santana., Bahia. 
extension actions aimed at combating the illegal trade of teeth through visits to cemeteries in the city in order to promote awareness among gravediggers about the ethical, legal and biological precepts that involve the trade of teeth. teeth.

Keywords: Dentistry, Ethics, Biosafety

\section{INTRODUÇÃO}

A criação dos Biobancos de Dentes Humanos (BDH) nas Instituições de Ensino Superior no Brasil implica função ética de buscar minimizar o comércio ilegal no que concerne a utilização de estruturas dentárias nos cursos de Odontologia. Ademais, desenvolver a percepção dos discentes e docentes para a coleta de dentes destinados a ensino e pesquisa científica, em concordância com as leis vigentes no país, ao mesmo tempo em que orienta sobre a Biossegurança. (PEREIRA, 2012)

Mas, muitos acadêmicos e profissionais obtêm, junto a outros profissionais, tais como os coveiros, dentes cuja procedência não está sendo registrada conforme as determinações legais. Seja no comércio ilegal ou na profanação de túmulos ou ossuários. (PEREIRA, 2012)

A origem dos dentes utilizados em estudos pré-clínicos e pesquisas deve ser comprovado e seguir a lei de Transplantes Brasileira que é enfática ao relatar no art. $6^{\circ}$ que "é vedada a remoção post mortem de tecidos, órgãos ou partes do corpo de pessoas não identificadas" (lei 9434 de 04/02/1997). Além disso, o Código Penal também prevê pena de 1 a 3 anos de reclusão para aqueles que violarem sepultura (Artigo 210) e o Conselho Nacional de Saúde exige os termos de consentimento livre e esclarecido dos sujeitos como forma de "respeito à dignidade humana" (Resolução No 466 de 12/12/2012). Além disso, o aspecto relacionado ao risco de contaminação cruzada deve ser levado em conta tendo em vista que tecidos presentes na estrutura dental, como a polpa e a raiz, podem conter patógenos como o vírus da hepatite B, vírus HIV e inúmeros outros de origem hematogênica (WHITE; HAYS, 1995).

Por esses motivos, implantação de um Biobanco de Dentes Humanos nas Faculdades de Odontologia é a principal forma de comprovação da origem dos dentes utilizados por estudantes, pois todos os dentes armazenados no BDH devem ter doação consentida por seu responsável. O doador, ciente dos motivos da escolha da exodontia, autoriza e legaliza a doação por meio do Termo de Consentimento Livre e Esclarecido. 
Por ser uma instituição que lida com a conscientização, arrecadação, empréstimo e descarte de dentes, requer uma visão de abrangência que envolva todos os agentes que se comprometam com qualquer processo referente ao BDH. (NASSIF et al., 2003).

Apesar disso, é evidente que a conscientização sobre a importância da origem dos dentes também deve ocorrer com os acadêmicos, mas é preciso ir além. Existe a necessidade de conscientizar os coveiros como um meio de minimizar o comércio ilegal de dentes, tratando diretamente com o "comerciante". Nessa perspectiva, este relato de experiência tem como objetivo demonstrar uma ação extensionista, que, através de práticas de conscientização, alcançou esses atores que corroboram com o cenário atual de comercialização de órgãos e infração da lei. Ademais, tem como finalidade apresentar a importância de informar sobre a irregularidade desta prática, bem como, a promoção do conhecimento sobre o Biobanco de Dentes Humanos como um setor regulamentado para atender as necessidades acadêmicas de acordo com os preceitos éticos, legais e biológicos.

\section{METODOLOGIA}

O levantamento bibliográfico foi concretizado através da busca de leis que regem acerca do assunto e da pesquisa sobre o Biobanco de Dentes Humanos nas bases de dados PubMed e Scielo. Foi fundamental para confecção de material didático (folders e cartazes) com orientações sobre a prática do comércio ilegal de dentes bem como suas consequências do ponto de vista da biossegurança, ética e legal, além de informações básicas sobre o funcionamento do BDH (Figura 1). Para a realização das visitas aos cemitérios, foi preciso efetivar uma pesquisa acerca da localização dos mesmos na cidade de Feira de Santana. Posteriormente, os folders foram elaborados e distribuídos para os coveiros e funcionários, sendo então, algumas orientações passadas de forma verbal.

O levantamento constatou um total de 6 cemitérios em Feira de Santana, sendo eles: São Jorge (R. Bartolomeu de Gusmão - Sobradinho), São João Batista (Av. Gov. Joao Durval Carneiro, 7662 - Alto do Papagaio), Piedade (R. Prof ${ }^{a}$. Edelvira de Oliveira, S/N - Centro), Jardim Celestial (R. Nova Esperança, 104, bairro Sim), Jardim das Flores (Rod BR-116, - Zona Rural) e cemitério Paroquial das Itapororocas (Estrada da Pedra Ferrada). Apesar de poucos, o contato foi dificultado pelo acesso a esses cemitérios (em 
sua maioria localizado longe do centro da cidade), além da dificuldade de acesso aos coveiros. Porém, os administradores e funcionários se mostraram dispostos a receber as orientações e se comprometeram a fiscalizar de forma mais efetiva essa prática ilegal.

\section{Figura 1}

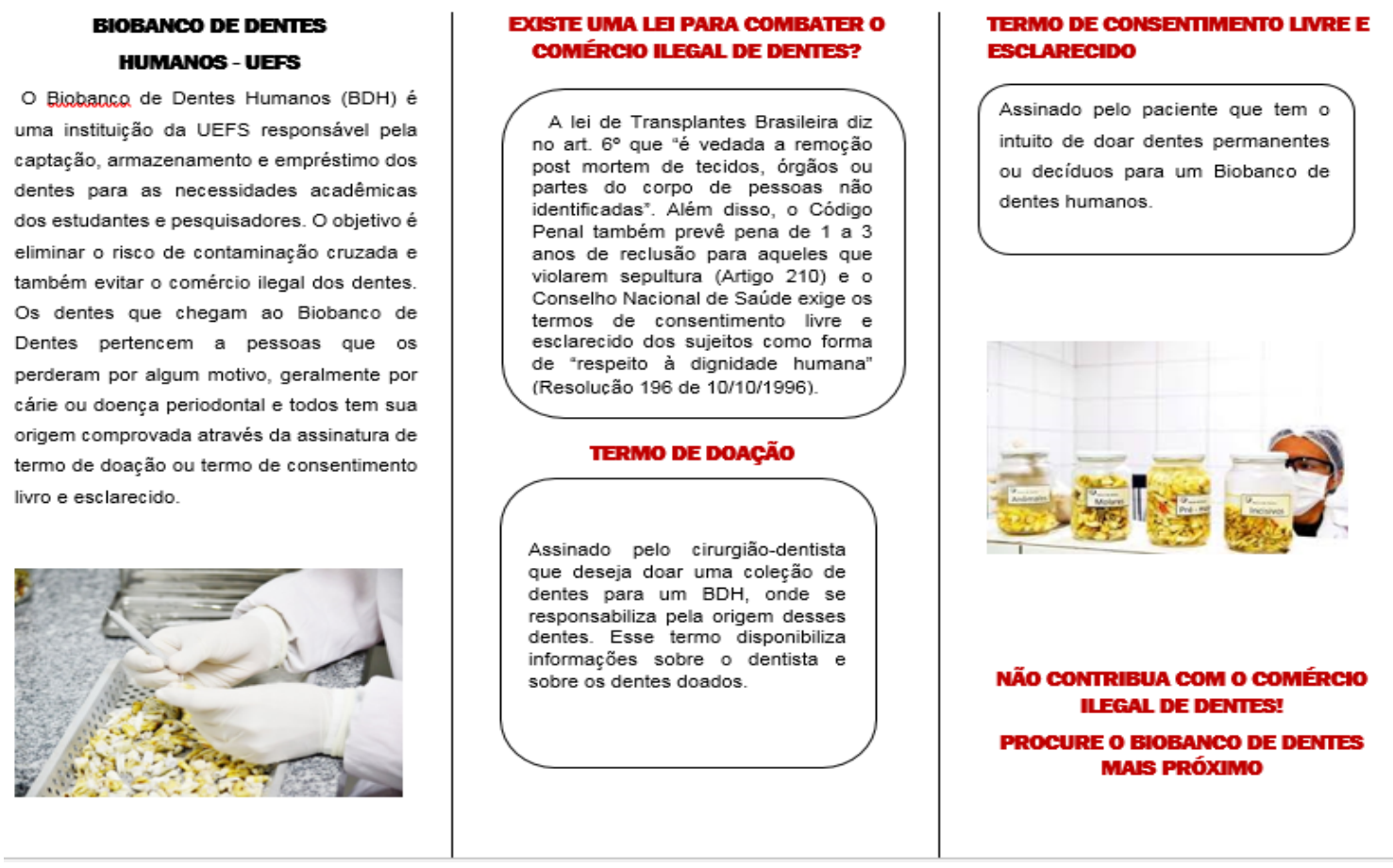

Fonte: acervo dos autores

\section{RESULTADOS E DISCUSSÃO}

Os cursos de Odontologia atuais utilizam dentes humanos em seus estudos préclínicos e pesquisas como uma forma de aproximar o estudante e o pesquisador da realidade existente na cavidade oral do paciente. Porém, muitas vezes esses dentes apresentam origem indevida quanto aos preceitos legais e éticos conquistados através do comércio ilegal de dentes oriundo de cemitérios. Tendo em vista essa situação atual constatada em diversas faculdades de Odontologia, é fundamental a existência do Biobanco de Dentes Humanos (BDH), instituição sem fins lucrativos que visa captar, armazenar e emprestar dentes de forma segura e ética. (PEREIRA, 2012).

O BDH também tem papel pertinente na orientação, sendo de suma importância o oferecimento de campanhas de conscientização para a divulgação do BDH como uma ferramenta capaz de combater o comércio ilegal, principalmente quando relacionadas ao "comerciante" (coveiro) e ao "consumidor" (estudante) dos dentes, visto 
que esses são os usuários desse serviço. Por isso, percebe-se a necessidade de denunciar irregularidades e de concentrar ações voltadas para os coveiros. (PEREIRA, 2012)

As ações extensionistas executadas tem caráter educativo com a pretensão de proporcionar informações importantes a comunidade externa, ultrapassando os muros da Universidade para devolver a população, em forma de conhecimento, parte do estudo acadêmico desenvolvido através do BDH. Assim, propiciando novas experiências ao discente, através de ações sociais em que foi possível estimular habilidades de criatividade, seleção e estudo do conteúdo, além de planejamento e domínio da fala.

Os impactos ocasionados pela efetivação do trabalho extensionista foram, principalmente, a conscientização de 12 coveiros e 6 funcionários recepcionistas e administradores dos cemitérios sobre aspectos de biossegurança bem como, informações judiciais a respeito das leis que podem ser infringidas caso haja o comércio de dentes. Com o levantamento bibliográfico realizado foi possível perceber a importância do papel do Biobanco de Dentes Humanos como um setor responsável por educar a comunidade interna e externa à universidade e assim, promover o combate ao comércio ilegal de dentes que ainda existe em muitas universidades.

No período de efetivação das ações foi possível obter um maior conhecimento sobre biossegurança, anatomia dentária, regulamentação do BDH, e ainda conscientizar acerca da importância da doação de dentes e valorização do dente como órgão do corpo humano. Por meio das atividades desenvolvidas no BDH para a manutenção, separação e catalogação de dentes foi possível ter contato com a diversidade anatômica dos dentes e assim aprofundar o conhecimento da anatomia dentária. Nesse mesmo aspecto, constatou-se na prática a importância do conhecimento sobre biossegurança no manuseio de dentes para evitar contaminações.

\section{CONCLUSÃO}

A experiência relatada foi de grande valia para o acadêmico em formação, tendo em vista colaboração com a construção de um profissional com uma visão ética, proporcionando vivências em torno da realidade local, e contribuindo para mudanças em torno do problema encontrado. Assim, o acadêmico se torna ciente do seu papel nas ações educativas junto a população ao seu redor. Dessa forma, ações extensionistas como essa são importantes para informar a população de que o dente é um órgão do corpo humano e como tal, deve ser respeitado. 


\section{REFERÊNCIAS}

PEREIRA, D. Q.Banco de dentes humanos no Brasil: revisão de literatura. Rev. ABENO, v.12, no.2, p.178-84, 2012.

WHITE, R. R.; HAYS, G. L. Failure of Ethylene Oxide to Sterilize Extracted Human Teeth. Dent. Mater., Kidlington, v. 11, no. 4, p. 231-233, July 1995.

NASSIF A.C.S., et al. Estruturação de um banco de dentes humanos. Pesqui Odontol Bras, v.17, no.Supl 1, p.70-4, 2003.

BRASIL. Resolução N 466 de 12 de dezembro 2012 do Conselho Nacional de Saúde. Diário Oficial da União, n. 12, s. 1, p. 59, 2013.

BRASIL. Lei no 9.434, de 4 de fevereiro de 1997. Dispõe sobre a remoção de órgãos, tecidos e partes do corpo humano para fins de transplante e tratamento e dá outras providências. DOU. 6 fev. 1997; 89 (25) Seção 1:2191-3. 